\title{
Influence of Shade and Bed Types on Attaining Optimum Temperature for The Germination of Peach (Prunus Persica L. Batsch) Seeds at Holetta, Central Ethiopia
}

\author{
Habtam Setu ${ }^{1}$, Tajebe Mosie ${ }^{1}$, Kidist Firdie ${ }^{1}$, Tenagne Eshete ${ }^{1}$ \& Getaneh Sileshi ${ }^{1}$ \\ ${ }^{1}$ Ethiopian Institute of Agricultural Research, Holetta Agricultural Research Center, Ethiopia \\ Correspondence: Habtam Setu, Ethiopian Institute of Agricultural Research, Holetta Agricultural Research Center, \\ P.O.Box. 31 Holetta, or 2003 Addis Ababa, Ethiopia. E-mail: habtamsetu@gmail.com
}

Received: February 20, 2020 Accepted: March 5, 2020 Online Published: May 5, 2020

\begin{abstract}
Poor germination of peach seeds is the major limiting factor for rootstock production under the Holetta condition because of the seed dormancy problem. Stratification plays an important role in shortening the dormancy and increasing the germination of peach seeds. The study aimed to find easy stratification techniques for the germination of peach seeds using shade and different bed types. The experiment was carried out at the Holetta Agricultural Research Center in two successive years of 2017 and 2018. We got seeds used for this study from peach trees, which were well adapted for the Holetta area. It was arranged in a completely randomized design with five treatments of under tree shade on a flatbed, under tree shade in sunken bed, out of tree shade on a flatbed, out of tree shade in sunken bed and refrigerator as a standard check. They put all treatments except the refrigerator under the grass shade constructed $1 \mathrm{~m}^{3}$ wide. The treatments replicated four times, and each replication contained 200 seeds. The results showed that temperature is the most important factor affecting the germination percentage of the peach seeds. Seeds sown under the temperature close to $8{ }^{\circ} \mathrm{C}$ which is in the refrigerator found to have better germination percentage $(47.1 \%)$ followed by the seeds sown in the grass shade under the tree shade both on sunken $(35.8 \%)$ and flatbeds (34.9\%). Peach seeds stratified in the refrigerator had good germination percentage whereas survival of the seedling was better at out of tree shade in sunken bed and out of tree shade on the flatbed. Even though the germination percentage was lower and the germination speed index was higher than the refrigerator. Seeds stratified at a temperature of above $17^{\circ} \mathrm{C}$ experienced a poor germination percentage.
\end{abstract}

Keywords: Germination, peach seed, stratification, temperature, tree shade

\section{Introduction}

Peach (Prunus persica L. Batsch) requires low temperature to break the dormancy of seeds and buds resulting in seed germination and flowering (Americo et al., 2013). The low temperature triggers internal mechanisms that change the nature and level of growth regulators involved in the dormancy's control processes (Kester et al., 1977). Seed dormancy and germination are complex features relating to higher plants like peach, which are influenced by factors related to environmental conditions (Bentsink \& Koornneef, 2008). A high germination percentage coupled with a desirable growth habit is the basic requirement of a good seedling rootstock (Thakur, 2015). Seeds of temperate fruits like peach trees enter dormancy at the time of fruit harvest and required exposure to cool temperature and moist environment that provides the stimulus required for overcoming dormancy, increase germination and produce normal seedlings (Perez-Gonzalez, 1997; Wagner Junior et al., 2013). Seeley et al. (1998) and Martinez-Gomes and Dicenta (2001) characterized the phenomenon in peach's seed germination as influenced by seed coat dormancy (external), inhibition of germination manifested with a hormonal nature, and embryo dormancy (internal) which inhibited with a genetic nature expressed mainly in later plant growth. According to Webb et al. (1962), the low temperatures associated with moisture change the equilibrium among growth inhibitors and promoters, resulting in germination.

Seeds not exposed to the adequate conditions for overcoming dormancy may not germinate or may produce abnormal seedlings, with physiological symptoms of dwarfism (Hartmann et al., 1997). It associates such abnormalities of physiological nature with a delay of seedling growth, reducing the plant stand in the nursery (Martins et al., 2014). Stratification is the method used to overcome external dormancy of seed in Prunus species (Mehanna et al., 1985; Frisby \& Seeley, 1993; Bewley et al., 2013; Seeley et al., 1998), which involved storing seeds with an equal volume of moist medium for a period at a cold temperature. Peach's seeds germination 
becomes more complicated in tropical countries. Despite the difficulty in the germination of its seeds, farmers propagate local peach trees in some highlands of Ethiopia. We also observe peach seedlings in the farmer's back yards that emerged under the shade of trees and near the fence. However, farmers do not raise seedlings deliberately because they need low temperatures under the refrigerator unaffordable to them. Therefore, the study aimed to find easy stratification techniques for the germination of peach seeds using shade and different bed types.

\section{Materials and Methods}

\subsection{Description of The Experimental Site}

We carried out the study at the Holetta Agricultural Research Center, which is located at an altitude of $2400 \mathrm{~m}$ above sea level, $9^{\circ} 00^{\prime} \mathrm{N}$ latitude and $38^{\circ} 30^{\prime} \mathrm{E}$ longitude. The annual rainfall of $1041.4 \mathrm{~mm}$ and the average annual minimum and maximum temperatures are $6.7^{\circ} \mathrm{C}$ and $21.7^{\circ} \mathrm{C}$, respectively (EIAR, 2017).

\subsection{Treatments and Experimental Design}

The experiment arranged in a completely randomized design (CRD) with five treatments of under tree shade on a flatbed (S1B1), under tree shade in sunken bed (S1B2), out of tree shade on a flatbed (S2B1), and out of tree shade in the sunken bed (S2B2), and refrigerator (standard check). The treatments were replicated four times, and each replication contained 200 seeds.

\subsection{Experimental Procedure}

The experiment was carried out for two successive years of 2017 and 2018 production seasons. We collected the matured and ripened peach fruits from adapted local peach trees around Medagudina area, Holetta District, Ethiopia. Then, the pulp was removed from the exocarp like and washed it with pure water and dried it under shade. Then after we broke the exocarp carefully and removed the immature and damaged seeds since they are not viable. We disinfected the pure seeds with $0.05 \%\left(5 \mathrm{ml} \mathrm{lit}^{-1}\right.$ of water) sodium hypochlorite solution for one hour and washed with distilled water repeatedly to remove the chemical from the seed. We then sowed the seeds in the plastic box (crate) which filled with sterilized (boiled) sand and arranged according to the treatment setup. The plastic box in which we sowed the seeds put in the sunken bed had $10 \mathrm{~cm}$ depth. All treatments except refrigerators were put under the grass shades constructed from grass (Guizotia abyssinica in Amharic called 'Senbelet') and stake with $1 \mathrm{~m}^{3}$ size and based on the treatment arrangement some grass shades are put under avocado tree shade and others are out of the tree shade. We recorded the temperature of the shades daily in the morning, mid-day and evening while we adjusted the temperature of the refrigerator at $8{ }^{\circ} \mathrm{C}$. We sprayed water as required for each treatment to keep the sand moistened. The germinated seeds were collected carefully and transplanted to a plastic bag filled with the proportion of 2:1:1 topsoil, sand and farmyard manure, respectively.

\subsection{Data Collection and Analysis}

Data were taken for each treatment from the commencement of germination and at every four days interval until the completion of germination.

Germination Speed (Rate) Index (GSI): reflects the percentage of seed germination on each day of the germination period (Esechie, 1994) and calculated as the formula presented by Maguire (1962), expressing the summation of the ratio between the numbers of germinated seeds and the evaluation days.

$$
G S I=\frac{\text { Number of seedlings at } 1^{\text {st }} \text { count }}{\text { days to } 1^{\text {st }} \text { count }}+--+\frac{\text { Number of seedling at final count }}{\text { days to final count }}
$$

The Mean Germination Time: represents the average time a seed lot requires to initiate and end germination (Orchard, 1977) and calculated using the formula stated by Labouriau (1983):

$$
M G T=\frac{\Sigma(t * n)}{\Sigma n}
$$

Where $t$ is the time in days starting from sowing date (day 0 ) to the end of the germination test, and $n$ is the number of seeds completing germination on day $t$.

Germination Percentage: was calculated by dividing the number of germinated seeds to the total number of sample seeds sown (Al-Mudaris, 1998).

$$
\text { Germination percentage }=\frac{\text { Number of germinated seed }}{\text { Total number of seed sown }} \times 100
$$

Percent Survival: was calculated by dividing the number of survived seedlings after transplanted to polyethylene bags to the total number of germinated seeds (seedlings). 


$$
\text { Percent survival }=\frac{\text { survived seedlings after transplanted }}{\text { Total number of germinated seeds }} \times 100
$$

Mean Temperature: was obtained from the recordings of daily minimum and maximum temperatures.

The data analysis was made by using a statistical analysis system (SAS 9.3). The comparison of treatment means was done by LSD test at 5\% probability level.

\section{Result ad Discussion}

\subsection{Mean Temperature}

We present the result for the influence of shade and bed type for a mean temperature of 2017 and 2018 growing seasons in Table 1. There was no significant difference in mean temperature between treatments under tree shade on a flatbed (S1B1) $\left(16.56^{\circ} \mathrm{C}\right)$, out of tree shade on a flatbed (S2B1) $\left(16.63^{\circ} \mathrm{C}\right)$ and out of tree shade in the sunken bed (S2B2) $\left(16.63^{\circ} \mathrm{C}\right)$ in the 2017 production season in which significantly lower mean temperature was recorded for under tree shade in sunken bed (S1B2) $\left(16.47^{\circ} \mathrm{C}\right)$. In the 2018 production season, we recorded the lowest temperature for S1B1 $\left(17.60^{\circ} \mathrm{C}\right)$ treatment, which does not significantly differ from S1B2 $\left(17.65^{\circ} \mathrm{C}\right)$. The highest temperature was experienced for treatments, $\mathrm{S} 2 \mathrm{~B} 2\left(17.86^{\circ} \mathrm{C}\right)$ and $\mathrm{S} 2 \mathrm{~B} 1\left(17.76^{\circ} \mathrm{C}\right)$ which is significantly different. There was no significant difference between treatments $\mathrm{S} 1 \mathrm{~B} 1\left(17.07{ }^{\circ} \mathrm{C}\right)$ and $\mathrm{S} 1 \mathrm{~B} 2\left(17.05{ }^{\circ} \mathrm{C}\right)$ on over year combined result of mean temperature and the same is true for treatments, $\mathrm{S} 2 \mathrm{~B} 1$ and $\mathrm{S} 2 \mathrm{~B} 2$ which is $17.19^{\circ} \mathrm{C}$ and $17.24{ }^{\mathrm{O}} \mathrm{C}$ respectively. Although investigations have been done on the low-temperature stratification of peach seeds to overcome dormancy (Sharma \& Singh, 1978; Bewley et al., 2013; Americo et al., 2013). Overall treatments located out of shade both on the flat and sunken bed recorded significantly higher temperatures followed by those treatments in the shade and the control as stated in Figure 1. Here remember we expect the temperatures recorded for each respective treatment to control the germination speed index, mean germination time, percentage germination, and percentage survival of seedlings. Seeds can germinate in a range of temperatures from approximately $10^{\circ} \mathrm{C}$ to $35^{\circ} \mathrm{C}$ (Biggs \& Langan, 1962). Abbot (1955) also reported that $-5^{\circ} \mathrm{C}$ is the least effective temperature for seed germination and temperatures higher than $17{ }^{\circ} \mathrm{C}$ could re-impose the seed dormancy. The growth capacity of the seedlings was markedly decreased by a temperature greater than $25.5{ }^{\circ} \mathrm{C}$ during the germination period (Biggs \& Langan, 1962; Afroze \& O’Reilly, 2016). The high germination percentages observed at $5 / 15^{\circ} \mathrm{C}$ and $10 / 20{ }^{\circ} \mathrm{C}$ coincided with the temperatures of April and May in natural habitat. The low germination percentage observed at $15 / 25^{\circ} \mathrm{C}$ and $20 / 30^{\circ} \mathrm{C}$ was possibly caused by secondary dormancy (Tang et al., 2019).

\subsection{Percentage Germination}

We express the result for percentage germination for the influence of shade and bed type below in Table 1. There was a significant difference between treatments in the 2017 growing season in which we recorded the highest percentage germination for the refrigerator (47.38) followed by S1B1 (45.38) and S1B2 (40.63). Stratification for 30 days at $5{ }^{\circ} \mathrm{C}$ shows the highest germination percentage and highest survival of pomegranate seedlings (Rawat et al., 2010). Treatments put out of tree shade both on sunken and flatbed recorded the lowest germination percentage in which S2B2 (8.13) followed by S2B1 (19.00) but, still, there was a highly significant difference. In 2018 , there was a relatively lower germination percentage of the refrigerator as compared to the 2017 growing season, even if the rest of the treatments remain similar to the previous year. This is might be because of factors other than the higher temperature recorded in 2018 inhibited the germination potential of the seeds. The refrigerator (46.75) still maintains a higher germination percentage compared to other treatments and followed by S1B1 (45.38) and S1B2 (40.63). The inhibitive influence of cool temperatures on seed germination and subsequent seedling development is temporary, whereas the inhibitive influence of warm temperatures is a more lasting nature (Biggs and Langan, 1962). Overall, the combined analysis showed that a significant difference was observed between all the treatments except between the refrigerator (47.06) and S1B1 (45.38). Selim et al. (1998) also found stratification of peach seeds at lower temperatures increased the content of growth promoters such as gibberellins and indole acetic acid and reduced the content of growth inhibitors such as abscisic acid. Apart from temperature, the breaking of dormancy is governed by other environmental cues like water potential light (Holmes \& McCartney, 1975), nitrate, hormones, and some smoke components (Bewley et al., 2013) that should be studied further in the future. The microclimate that created under the tree contributed to the control of seed dormancy status and germination primarily through moisture content and temperature (Finch-Savage, 2004). Besides, the physical attributes of the seed, such as seed coat permeability, can mitigate these microclimate effects. The physiological state of the seed, including its genetic background and maternal and environmental effects during development and maturation, influences the initial dormancy level (Allen et al., 2007; Bewley et al., 2013). 


\subsection{Percentage of Survival}

Mean comparison of percentage survival of the peach seedlings were done for the two growing seasons as affected by the shade and different bed types (Table 1). There was no significant difference in the percentage of seedling survival between S1B1 (72.02\%), S1B2 (82.61) and control (76.55\%) treatments in 2017 which is the same is true between S2B1 and S2B2. The highest survival percentage was recorded for treatments laid out of shade that is S2B2 (100\%) and S2B1 (99.07\%), respectively, in descending order. In the 2018 production season, the nonsignificant difference was recorded between treatments except for S2B2 and the control. Still, the highest survival rate is recorded for S2B2 (95.42\%) followed by S1B1 (87.34\%) and S2B1 (84.11\%). Over year combined result showed that $97.71 \%$ survival rate was recorded for seeds sown on out of tree shade in sunken bed (S2B2) followed by out of tree shade on a flatbed (S2B1) which is $91.59 \%$ and under tree shade in sunken bed (S1B2) $82.74 \%$ as stated in Figure 1. The reason for this might be because of the lower temperature fluctuation between while the seed germination chamber (crate) and the greenhouse after transplanting. Since after germination, seedlings may fail to emerge or survive due to the interacting effect of environmental signal and biological responses (Bewley et al., 2013). This finding is in agreement with previous reports (Chauhan et al., 1961; Pollock, 1962) that rather warm temperatures during peach seed germination have an antagonistic effect on seedling growth and development. Stratification length strongly influenced the later growth and performance of the seedlings (Vahdati et al., 2012). Martinez-Gomes and Dicenta (2001) also observed that reduced plant growth in seedlings was treated for low temperatures for a short period as compared to a longer period.

Table 1. Influence of shade and bed type for mean temperature, germination percentage, percent survival, germination speed index, and mean germination time of peach seed stratification for the two growing seasons.

\begin{tabular}{lcccccccccc}
\hline Treatments & \multicolumn{2}{c}{$\begin{array}{c}\text { Germination } \\
\text { speed index }\end{array}$} & \multicolumn{2}{c}{$\begin{array}{c}\text { Mean } \\
\text { germination time }\end{array}$} & \multicolumn{2}{c}{$\begin{array}{c}\text { Average } \\
\text { temperature }\end{array}$} & \multicolumn{2}{c}{$\begin{array}{c}\text { Germination } \\
\text { percentage }\end{array}$} & Survival percent \\
& 2017 & 2018 & 2017 & 2018 & 2017 & 2018 & 2017 & 2018 & 2017 & 2018 \\
\hline S1B1 & $2.84 \mathrm{a}$ & $0.97 \mathrm{~b}$ & $33.79 \mathrm{c}$ & $47.72 \mathrm{~b}$ & $16.56 \mathrm{a}$ & $17.60 \mathrm{~b}$ & $45.38 \mathrm{ab}$ & $45.38 \mathrm{ab}$ & $72.02 \mathrm{~b}$ & $87.34 \mathrm{ab}$ \\
S1B2 & $2.58 \mathrm{a}$ & $1.06 \mathrm{~b}$ & $33.54 \mathrm{c}$ & $46.33 \mathrm{~b}$ & $16.47 \mathrm{~b}$ & $17.65 \mathrm{~b}$ & $40.63 \mathrm{~b}$ & $40.63 \mathrm{~b}$ & $82.61 \mathrm{~b}$ & $82.86 \mathrm{~b}$ \\
S2B1 & $1.39 \mathrm{~b}$ & $1.49 \mathrm{a}$ & $40.70 \mathrm{bc}$ & $44.06 \mathrm{~b}$ & $16.63 \mathrm{a}$ & $17.76 \mathrm{ab}$ & $19.00 \mathrm{c}$ & $19.00 \mathrm{c}$ & $99.07 \mathrm{a}$ & $84.11 \mathrm{ab}$ \\
S2B2 & $0.45 \mathrm{c}$ & $1.04 \mathrm{~b}$ & $42.36 \mathrm{~b}$ & $47.03 \mathrm{~b}$ & $16.63 \mathrm{a}$ & $17.86 \mathrm{a}$ & $8.13 \mathrm{~d}$ & $8.13 \mathrm{~d}$ & $100 \mathrm{a}$ & $95.42 \mathrm{a}$ \\
Refrigerator & $0.29 \mathrm{c}$ & $0.29 \mathrm{c}$ & $72.42 \mathrm{a}$ & $78.12 \mathrm{a}$ & $8.00 \mathrm{c}$ & $8.00 \mathrm{c}$ & $47.38 \mathrm{a}$ & $46.75 \mathrm{a}$ & $76.55 \mathrm{~b}$ & $77.57 \mathrm{~b}$ \\
LSD (5\%) & 0.62 & 0.40 & 7.93 & 15.00 & 0.09 & 0.2 & 5.62 & 5.81 & 11.47 & 11.88 \\
Sig. level & $* *$ & $* *$ & $* *$ & $* *$ & $* *$ & $* *$ & $* *$ & $* *$ & $* *$ & $\mathrm{NS}$ \\
CV (\%) & 26.7 & 27.04 & 11.55 & 18.49 & 0.38 & 0.81 & 11.36 & 11.79 & 8.65 & 9.03 \\
\hline
\end{tabular}

Means of the same main effect followed by the same letter within a column are not significantly different at $5 \%$ level of significance. Where S1B1-Under tree shade on a flatbed; S1B2-Under tree shade in sunken bed; S2B1Out of tree shade on a flatbed; and S2B2-Out of tree shade in the sunken bed; $* *=$ significant at $\mathrm{P}<0.01$ probability level; * = significant at $\mathrm{P}<0.05$ probability level; $\mathrm{Ns}=$ non-significant at $\mathrm{P}<0.05$ probability level; $\mathrm{LSD}=$ least significant difference; and $\mathrm{CV}=$ Coefficient of variation.

\subsection{Germination Speed Index (GSI)}

The result for GSI due to the influence of shade and bed type is presented above in Table 1. In 2016 there is no significant difference in GSI between treatments S1B1 and S1B2 which is the same is true for treatments S2B2 and the control. The highest GSI is recorded for S1B1 (2.84) followed by S1B2 (2.58) and S2B1 (1.38). The lowest germination speed index is experienced in the control treatment which is 0.28 . In 2017 growing season relatively lower germination speed index was recorded for all treatments except for S2B2 and control. Here the significant difference is observed except for treatments S1B1 and S1B2. The highest germination speed index is recorded for S2B1 (1.49) followed by S1B2 (1.05) and S2B2 (1.03). Still, the lowest GSI is recorded for the control (0.29) followed by S1B1 (0.97). Under the combined result, there was a significant difference is observed between treatments except for S1B1 and S1B2. Here the highest GSI is recorded for S1B1 (1.90) followed by S1B2 (1.82) even if there is no statistical difference between them. This variation might be because of the length of periods that the seeds we exposed to stratification (Finch-Savage, 2004; Rawat et al., 2010), and also be cues the genetic 
component that can influence entire population of seed or individual seeds within a seed lot (Geneve, 2003; Americo et al., 2013).

\subsection{Mean Germination Time (MGT)}

The influence of shade and bed type on MGT was presented in Table 1. There is no significant difference in MGT between treatments S1B1 (33.79), S1B2 (33.54) and S2B1 (40.70) in 2017 growing season in which it records the highest MGT for the control which is 72.42 followed by S2B2 (42.36). The lowest MGT was recorded for S1B2 (33.54) followed by S1B1 (33.79) which was not significantly different. In 2018 significant difference was not observed between treatments except for the control (78.12) which was significantly higher. Overall, the combined analysis showed that it recorded the highest mean germination time for the refrigerator (75.27) followed by S2B2 (44.70) and S2B1 (42.38) even if no significant difference was observed between treatments except for the control. The lower the MGT, the faster a population of seeds has germinated (Al-Mudaris, 1998) but this variation might be because of the difference in dormancy type that needs various lengths of periods of exposure to low temperature (Rawat et al., 2010). In addition to this, such germination time variation may encountered due to the water content of the seeds after ripening since at higher water contents dormancy is maintained or secondary dormancy may be induced and if seeds become too dry after-ripening is delayed or prevented (Vahdati et al., 2012; Bewley et al., 2013).

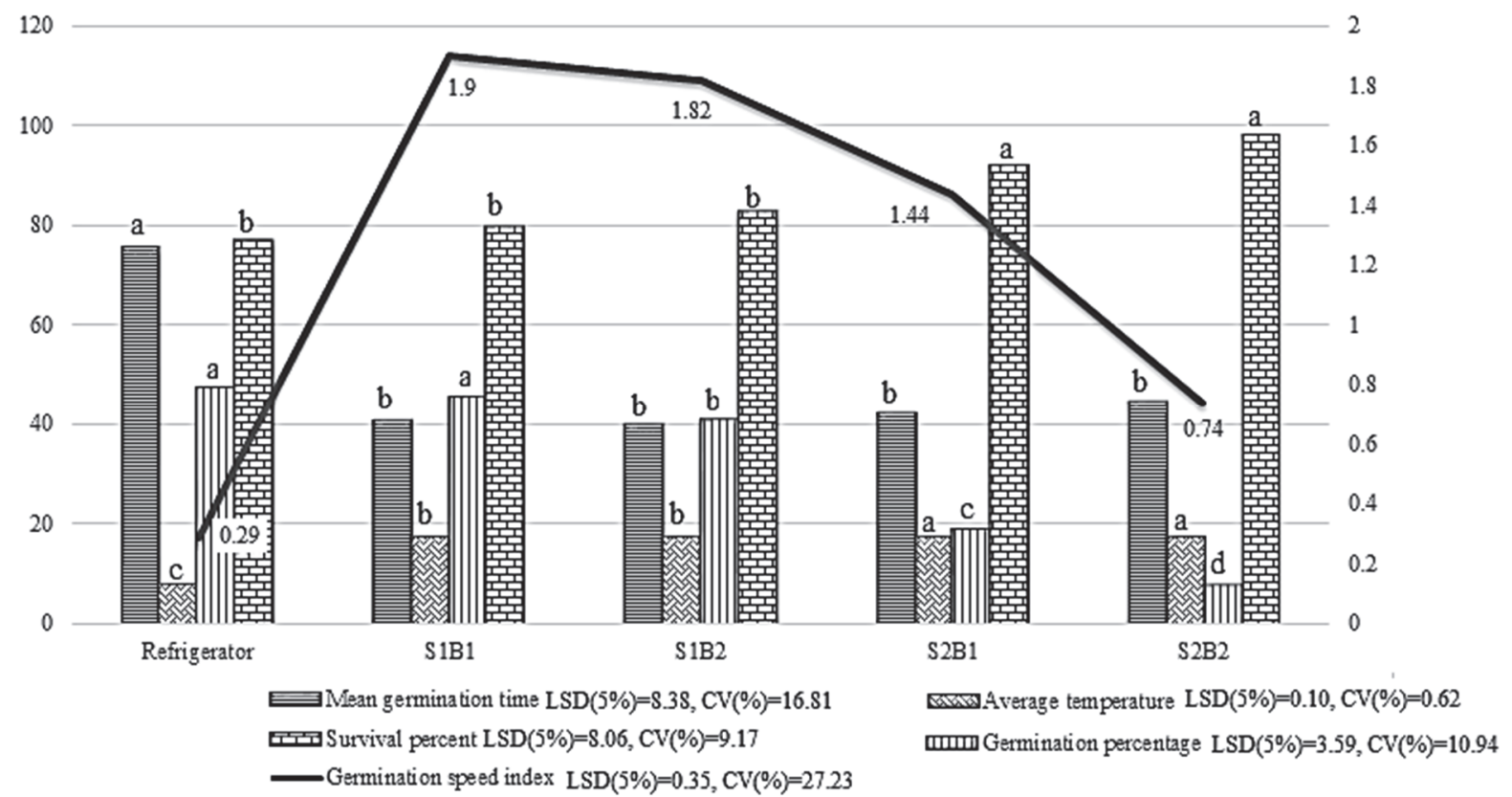

Figure 1. Combined analysis on the influence of shade and bed type for mean germination time, mean daily temperature, germination percentage, percent survival, and germination speed index peach seed stratification

Note: Where S1B1-Under tree shade on a flatbed; S1B2-Under tree shade in sunken bed; S2B1-Out of tree shade on a flatbed; and S2B2-Out of tree shade in the sunken bed; LSD = least significant difference; and CV = Coefficient of variation. Means of the same main effect followed by the same letter within a similar bar graph are not significantly different at a $5 \%$ level of significance.

\subsection{Association of Parameters}

As the result stated in Table 2 mean temperature has a significantly strong negative correlation with germination percentage and mean germination time (MGT) which is -0.49 and -0.80 respectively. This showed that when the average temperature increases, the germination percentage decreases and when the average temperature decreases, the mean germination time increase; whereas temperature had significantly strong positive correlation with germination speed index and percentage survival which is 0.48 and 0.38 respectively which showed that with increasing of temperature there is also increasing in percentage survival and germination speed index. Percentage survival has a non-significant negative correlation with GSI (-0.21) and MGT (-0.25) even if it has a significantly negative correlation with percentage germination $(-0.66)$. The complexity of the genetic component becomes 
apparent when considering the correlation of seed-chilled requirements of the plant (Powell, 1987); however, there was a low correlation between the time required to release dormancy in each seed (Kester et al., 1977).

Table 2. Pearson correlation coefficients (r) among the parameters for the influence of shade and bed type on peach seed stratification

\begin{tabular}{|c|c|c|c|c|c|}
\hline & $\begin{array}{l}\text { Germination } \\
\text { speed index }\end{array}$ & $\begin{array}{c}\text { Mean germination } \\
\text { time }\end{array}$ & $\begin{array}{l}\text { Average daily } \\
\text { temperature }\end{array}$ & $\begin{array}{l}\text { Germination } \\
\text { percentage }\end{array}$ & $\begin{array}{l}\text { Survival } \\
\text { percent }\end{array}$ \\
\hline $\begin{array}{l}\text { Germination speed } \\
\text { index }\end{array}$ & 1.00 & & & & \\
\hline $\begin{array}{l}\text { Mean germination } \\
\text { time }\end{array}$ & $-0.71 * *$ & 1.00 & & & \\
\hline $\begin{array}{l}\text { Average daily } \\
\text { temperature }\end{array}$ & $0.48 * *$ & $-0.80 * *$ & 1.00 & & \\
\hline $\begin{array}{l}\text { Germination } \\
\text { percentage }\end{array}$ & 0.15 & 0.30 & $-0.49 * *$ & 1.00 & \\
\hline Survival percent. & -0.21 & -0.25 & $0.38^{*}$ & $-0.66^{* *}$ & 1.00 \\
\hline
\end{tabular}

\section{Summary and Conclusion}

Stratification plays an important role as a stimulator that helps to break dormancy. The temperature is the most important factor affecting the germination percentage of the peach seeds. Seeds stratified under the temperature close to 8 OC found to have better germination percentage (47.06) followed by the seeds sown in the grass shade under the tree shade both sunken and flatbeds (45.38\%, and 40.63\%, respectively). Moreover, seeds stratified at the temperature above $17 \mathrm{OC}$ showed poor germination percentage. Peach seeds stratified in the refrigerator had good germination percentage whereas survival of the seedling was better at S2B2 and S2B1, even though the germination percentage was lower and the germination speed index was higher than the refrigerator. Therefore, peach seedlings grown for large-scale commercial purposes shall be stratified in the refrigerator or the place where the mean temperature below 8 OC. Peach seedlings grown for small-scale commercial purposes can be stratified in the grass shade under the tree shade on both flat and sunken beds. Although the percentage germination is a bit lower than seeds stratified in a refrigerator as shown in the result the grass shade under tree attains temperature to germinate peach seeds this will help smallholder farmers to grow peaches from seeds. As a result peach seedling grew for smallholder farmers especially where electric power is inaccessible and refrigerator is unaffordable could be stratified in a grass shade that is constructed by locally available materials under a tree shade in both flat and sunken beds as an alternative method to germinate peach seeds for the farmers.

\section{References}

Abbot, D. L. (1955). Temperature and the dormancy of apple seeds. Proc. XIV Intern. Hort. Congr. Scheveningen, (1), 746-753.

Afroze, F., \& O’Reilly, C. (2016). Effects of seed moisture content, warm, chilling, and exogenous hormone treatments and germination temperature on the germination of blackthorn seeds. Plant Biosystems, Rev. Ceres, Viçosa, 60(2), 234-241. https://doi.org/10.1080/11263504.2016.1179693

Allen, P. S., Benech-Arnold, R. L., Batlla, D., \& Bradford, K. J. (2007). Modeling of seed dormancy. In: Bradford KJ, Nonogaki H (eds), Seed development, dormancy and germination (pp 72-112). Blackwell Publishing, Oxford. https://doi.org/10. 1002/9780470988848

Al-Mudaris, M. (1998). Notes on various parameters recording the speed of seed germination. Der TropenlandWirt, 99, 147-154.

Americo W. J., Bruckner, C. H., Silva, J. O. C., Santos, C. E. M., Pimentel, L. D., \& Mazaro, S. M. (2013). Chilling requirement for seed germination and phenological observations on peach cultivars. Rev. Ceres, Viçosa, 60(2), 234-241. https://doi.org/10.1590/S0034-737X2013000200012 
Bentsink, L., \& Koornneef, M. (2008). Seed dormancy and germination. The Arabidopsis Book/American Society of Plant Biologists. https://doi.org/10.1199/tab.0119

Bewley, J. D., Kent, J. B. , Henk, W. M., \& Hiro, N. (2013). Seeds: Physiology of development, germination and dormancy, 3rd edition. Springer Science+Business Media, LLC. New York, USA. https://doi.org/10.1007/978-1-4614-4693-4

Biggs, R. H., \& Langan, M. C. (1962). Effect of Temperature on Germination of Okinawa Peach Seeds. Fla. State Hort. Soc. Proc., 75, 379-81.

Chauhan, K. S., Biggs, R. H., \& Sites, J. W. (1961). Temperature and dormancy of peach seeds. Proc. Fla. State Hort. Soc., (74), 367-371.

EIAR (Ethiopian Institute of Agricultural Research). (2017). Holetta Agricultural Research Center Progress Report. HARC, Holetta, Ethiopia.

Esechie, H. (1994). Interaction of salinity and temperature on the germination of sorghum. Journal of Agronomy and Crop Science, 172, 172-199.https://doi.org/10.1111/j.1439-037X.1994.tb00166.x

Finch-Savage, W. E. (2004). Models that describe germination behavior. In: Benech-Arnold R, Sanchez RA (eds), Handbook of Seed Physiology. Applications to agriculture (pp. 51-95). Food Products Press, New York. https://doi.org/10.1017/S0021859605235347

Frisby, J. W., \& Seeley, S. D. (1993). Chilling of endo-dormant peach propagules: Seed germination and emergence. J. Amer. Soc. Hort. Sci., 118, 248-252. https://doi.org/10.21273/JASHS.118.2.248

Geneve, R. L, (2003). Impact of temperature on seed dormancy. HortScince, 38(3), 336-341. https://doi.org/10.21273/HORTSCI.38.3.336

Hartmann, H. T., Kester, D. E., Davies, F. T., \& Geneve, R. L. (1997). Plant Propagation: Principles and practices. (6th ed). Prentice-Hall, USA. https://doi.org/10.1086/409642

Holmes, M. G., \& McCartney, H. A. (1975). Shade light quality. In: Smith H (ed), Light and plant development (pp 446-476). Butterworths, London. https://doi.org/10.1002/9780470988893

Kester D. E., Raddi, P., \& Assay, R. (1977). Correlation of chilling requirements of germination, blooming and leafing within and among seedling populations of almond. J. Amer. Soc. Hort. Sci., 102, 145-148.

Labouriau, L. G. (1983). A new line of research in the physiology of seed germination. Proceedings of the XXXIV National Botany Congress. SBB, Porto Alegre. Pp:11-50.

Maguire, J. D. (1962). Speed of germination-aid selection and evaluation for seedling emergence and vigor. Crop Science, 2, 176-177.

Martinez-Gomes, P., \& Dicenta, F. (2001). Mechanisms of dormancy in seeds of peach (Prunus persica L. Batsch) cv. GF305. Scientia Horticulturae, (91), 51-58. https://doi.org/10.1016/S0304-4238(01)00235-7

Martins, A. S., Bianchi, V. J., Zanandrea, I., Spinelli, V. M., \& Fachinello, J. C. (2014). Effects of seeds stratification on seedling emergence and initial development of peach rootstock. Cientifica (Jaboticabal), 42(2), 366-375.

Mehanna, H. T., Martin, G. C., \& Nishijima, C. (1985). Effects of temperature, chemical treatments and endogenous hormone content on peach seed germination and subsequent seedling growth. Hort. Science, 27, 63-73. https://doi.org/10.1016/0304-4238(85)90056-1

Orchard, T. J (1977). Estimating the parameters of plant seedling emergence. Seed Science and Technology, 5, 6169.

Perez-Gonzalez, S. (1997). Genotypic differentiation in temperature requirements for stratification in peach. Hort. Science, (32), 1064-1068. https://doi.org/10.21273/HORTSCI.32.6.1064

Pollock, B. M. (1962). Temperature control of physiological dwarfing in peach seedlings. Plant Physiology, 35, 190-197. https://doi.org/10.1104\%2Fpp.37.2.190

Powell, L. E. (1987). The hormonal control of bud and seed dormancy in woody plants. In: Davies P. J. (eds), Plant Hormones and their Role in Plant Growth and Development (pp. 539-552). Springer, Dordrecht. https://doi.org/10.1007/978-94-009-3585-3_28

Rawat, J. M. S., Tomar, Y. K., \& Vidyawati, R. (2010). Effect of stratification on seed germination and seedling performance of wild pomegranate. Journal of American Science, 6(5), 97-99. 
https://doi.org/10.7537/marsjas060510.15

Seeley, S. D., Ayanoglu, H., \& Frisby, J. W. (1998). Peach seedling emergence and growth in response to isothermal and cycled stratification treatments reveal two dormancy components. J. Am. Soc. Hort. Sci., 123(5), 776 780. https://doi.org/10.21273/JASHS.123.5.776

Selim, H. H., Kilany, O. A., Abdel-Wahab, W., \& Hassan, T. Y. (1998). Physiological studies on the propagation of Nemaguard peach seeds. Arab Universities Journal of Agricultural Sciences, 6, 249-266.

Sharma, H. C., \& Singh, R. N. (1978). Effect of stratification temperature, stratification period and seed coat on seed germination of peach cultivar 'Sharbati'. Scientia Horticulturae, 9, 47-53. https://doi.org/10.1016/03044238(78)90108-5

Tang, Y., Zhang, K., Zhang, Y., \& Tao, J. (2019). Dormancy-breaking and germination requirements for seeds of Sorbus alnifolia (Siebold \& Zucc. ) K. Koch (Rosaceae), a Mesic forest tree with high ornamental potential. Forest, 10, 319-320. https://doi.org/10.3390/f10040319

Thakur, B. (2015). Effect of growth regulator, scarification and thiourea on seed germination in peach (Prunus persica L. Batsch) rootstock Flordaguard. Int. Curr. Res. Aca., Rev., 3(5), 252-261.

Vahdati, K., Asadolah, A. A., Majid, R., Darab, H., \& Charles, L. (2012). Mechanism of seed dormancy and its relationship to bud dormancy in Persian walnut. Environmental and Experimental Botany, 75, 74-82. https://doi.org/10.1016/j.envexpbot.2011.08.006

Wagner, J. A., Horst, B. C., Osmar, C. S. J., Eduardo, M. S. C., Duarte, P. L., \& Sergio-Miguez, M. S. (2013). Chilling requirement for seed germination and phenological observations on peach cultivars. Revista Ceres, 60(2), 234-241. https://doi.org/10.1590/S0034-737X2013000200012

Webb, D. P., van Staden, J., \& Wareing, P. F. (1973). Seed dormancy in Acer: changes in endogenous cytokinins, gibberellins and germination inhibitors during the breaking of dormancy in Acer saccharum 'Marsh'. J. Exp. Botany, 24(78), 105-116. https://doi. org/10. 1093/jxb/24. 1. 105

\section{Copyrights}

Copyright for this article is retained by the author(s), with first publication rights granted to the journal.

This is an open-access article distributed under the terms and conditions of the Creative Commons Attribution license (http://creativecommons.org/licenses/by/4.0/). 